\title{
Políticas de la justicia criminal interétnica en Córdoba del Tucumán (siglos XVI y XVII)
}

\author{
Beatriz Bixio \\ Universidad Nacional de Córdoba \\ (Argentina)/CONICET
}

La jurisdicción de Córdoba fue un espacio colonial marginal en el que se pusieron en práctica tecnologías particulares del poder, implementadas desde las instancias políticas y judiciales locales, que resultaron extrañas y fueron objeto de repudio por parte de funcionarios superiores. En este contexto, interesa abordar un aspecto particular de esta problemática, aquel que se relaciona con la práctica de la justicia criminal interétnica, tal como surge del análisis de un conjunto de juicios substanciados en esta localidad a lo largo del siglo XVII. Interesa reconocer las estrategias del juego de la justicia local y los efectos que tuvo sobre la vida de los sujetos, el poder estatal y la estructura social. La compleja trama del derecho indiano ofreció un abanico variado y a veces contradictorio de posibilidades, de modo que el reconocimiento de las opciones normativas en cada situación permitirá anclar estas estrategias jurídicas en procesos históricos y sociales locales.

PALABRAS CLAVE: población indígena, poder, justicia criminal, derecho indiano, Tucumán colonial

Cordoba's jurisdiction was a marginal colonial space in which particular technologies of power were implemented from political and judicial bases. These technologies became evermore strange and were rejected by senior functionaries. It is relevant to analyze in this context one particular aspect of the issue: that related to the practice of interethnic criminal justice as it emerges from seventeenth-century judgments. Of notable interest are strategies of local justice and the impact they had on peoples's lives, reflecting state power and social structure. Indian rights were complex and varied affair. Close examination of normative options reveals details of juridical strategies operating within locally specific historical and social situations.

KEYWORDS: indigenous population, power, criminal justice Indian rights, Tucumán colonial period.

\section{Introducción}

Es común la observación según la cual en América Colonial, y en especial en las áreas marginales, la justicia actuó con libertad e independencia de la norma instituida. Este problema, que puede enunciarse como la relación entre el derecho y la práctica judicial (entendida como práctica política) debe ser historizado y regionalizado a fin de reconocer el conjun- 
to de "leyes" en sentido amplio a disposición en cada tiempo y lugar, y a partir de allí determinar el grado de aplicación de la norma indiana y el cumplimiento de la ley. En esta oportunidad interesa indagar en este aspecto a fin de reconocer las estrategias, la función y los efectos de la justicia en relación con la población indígena en una formación particular, Córdoba del Tucumán, y en un ámbito específico, el de la justicia criminal interétnica, o sea, en aquellas causas en las que participa la población indígena como demandante o demandada, como víctima o victimaria.

La gobernación del Tucumán, perteneciente al virreinato del Perú, abarcaba la amplia región del Noroeste y Centro de la actual República Argentina y fue incorporada a la Audiencia de Charcas por Real Cédula del 29 de agosto de 1563. La jurisdicción de la ciudad de Córdoba ocupó el punto extremo sur de esta gobernación, delimitada por el norte por Santiago del Estero (cabeza de la gobernación y asiento de las autoridades políticas y judiciales) y por el sur por un impreciso espacio que fue asiento de diferentes grupos indígenas denominados genéricamente "pampas".

En relación a la construcción del objeto de indagación, cabe indicar que en esta oportunidad interesa la práctica de la justicia, y en este sentido, si bien esta investigación se funda en la Historia del Derecho, se diferencia de ella pues la atención se focaliza en el juego de la justicia, en su ejercicio, en la puesta en funcionamiento de la ley en procesos judiciales particulares, contextuados históricamente, en los que nunca se debate un único conflicto (robo, asesinato, maltratos, etc.) sino que éste funciona como indicio de problemas más estructurales que surcan la sociedad en su conjunto. En este sentido, uno de los postulados explicativos más fructíferos para la comprensión de la especificidad de los problemas que estudiamos es el de marginalidad. Ya Assadourian había explicado en buena medida la modalidad que adquiere el sistema colonial en Córdoba del Tucumán del siglo XVII en virtud de su situación, alejada de los centros políticos más importantes, carente de metales preciosos, y por tanto, en el que la fuerza de trabajo indígena era la única riqueza explotable, de modo que la economía fue subsidiaria de la de otros centros, con los cuales constituyó una red de intercambio interregional (Potosí, Chile, Perú, Buenos Aires). ${ }^{1}$ Piana retomando este concepto, insiste en la marginalidad geográfica y en la política, demostrando que los vecinos se opusieron mediante diferentes estrategias a las visitas prometidas por el gobierno virreinal

1 Assadourian, Carlos Sempat: El sistema de la economía colonial. El mercado interior. Regiones y espacio económico, Nueva Imagen, México, 1983. 
que, a su vez, demostró poco interés en dicho control y dejó prácticamente en manos de los vecinos esta primera organización del sistema colonial. ${ }^{2}$ Córdoba no tenía riquezas ni representó una posición estratégica importante: fue una colonia de segunda categoría y, por ello, comparativamente, fue descuidada por las autoridades centrales, situación que la acerca a otras colonias marginales ${ }^{3}$ en las que la situación del indígena fue muy similar a la que se reconoce para esta jurisdicción. Esta noción de marginalidad aplicable a la dimensión geográfica, política y económica permite explicar, en buena medida, los atributos del sistema colonial regional y también las modalidades de las interacciones interétnicas. La productividad de esta categoría radica en que se erige en un organizador y orientador de las búsquedas históricas en cuanto advierte sobre la inconveniencia de referenciar este modelo colonial local con el peruano o de otros centros políticos. En efecto, a poco de indagar en el problema se observa que hasta las categorías sociales básicas (cacique, yanacona, encomendero, indio, pueblo de indios, república de indios, etc.) difieren radicalmente de las del Perú 4 , como así también difieren otras nociones, más afines al estudio de la justicia.

El derecho indiano constituyó una trama compleja en la que confluían leyes, costumbres y opiniones de juristas, por lo que ofreció un abanico variado de posibilidades frente a las cuales cada juez tenía a mano la opción entre normativas muchas veces confluyentes, otras contradictorias. ${ }^{5} \mathrm{Sin}$ embargo, no cualquier normativa pudo ser libremente aplicada pues el derecho indiano tenía preeminencia sobre los otros, indicación válida, incluso, para períodos previos a la Recopilación de $1680^{6}$. De este heterogéneo conjunto formaban parte las Partidas de Alfonso el Sabio, el derecho castellano, el canónigo, el indígena, reales células y pragmáticas e incluso, diferentes

2 Piana, Josefina: Los indígenas de Córdoba bajo el régimen colonial, Universidad Nacional de Córdoba, Argentina, 1992. Véase también González Rodríguez, Adolfo: "Encomienda y propiedad de la tierra en Córdoba durante los siglos XVI y XVII", Revista Complutense de Historia de América, N. ${ }^{\circ}$ 18, Madrid, 1992, págs. 143-157.

3 Véase Zabala Silvio: De la encomienda y la propiedad territorial de algunas regiones de la América española, México, 1945.

4 Bixio, Beatriz: "Los espacios de la exclusión en Córdoba del Tucumán", Anuario del Centro de Estudios Históricos Carlos A. Segretti, N. ${ }^{\circ}$, Córdoba, 2001, págs.15-38.

5 Tau Anzoátegui, Víctor: La ley en América Hispana. Del descubrimiento a la emancipación, Academia Nacional de Historia, Buenos Aires, 1992.

6 La ley 66, título 15 del libro II de la Recopilación, redactada en 1545, establece esta especificación. Véase Recopilación de las leyes de los reynos de las Indias, Madrid, 1943, pág. 343 y también Levaggi, Abelardo: Manual de historia del derecho argentino (castellano-indiano/ nacional),Edit. Depalma, Buenos Aires, Tomo I, 1998, pág. 155. 
normativas emanadas para ciertas regiones en particular por virreyes, audiencias, gobernadores e incluso cabildos, que tenían la facultad de dictar autos y bandos sobre la situación de los indígenas en sus jurisdicciones. Esta legislación, destinada a regular para cada caso y lugar, no fue el resultado de un plan orgánico de gobierno, por lo que, hasta la promulgación de la Recopilación (Real Cédula del 18 de mayo de 1680), las disposiciones se superponen, se contradicen y muchas veces resultan inaplicables; es así que para el período que estudiamos nos encontramos ante esta fuente normativa amplia, más aún si se tiene en cuenta que la ley no era la única fuente del derecho y las soluciones no se derivaban exclusivamente de ella sino que se conjugaron con el derecho natural, la equidad y la costumbre.

La legislación penal indiana es relativamente corta, aún cuando le corresponda un título específico de la Recopilación, el 8 del libro VII: "De los delitos y penas y su aplicación". Sólo en lo que se refiere a la protección de los indígenas la legislación penal es específica para las indias. Algunas normas advierten que deben ser amparados y favorecidos ${ }^{7}$, o que les está permitido la acusación sin fianza; se establece, incluso, que cuando el reo es indio y cuando la imputación es por injurias o golpes causados sin armas, queda excusada la formación de proceso y se lo releva de castigo. Es más, la legislación establece que se deben castigar con mayor rigor los delitos en que las víctimas son indios, respecto de los cometidos contra españoles. ${ }^{8}$

En relación con la región en estudio, y en particular con derecho penal interétnico, aparte de bandos y otras disposiciones menores emanadas por el gobernador o el cabildo de Córdoba, deberíamos incluir en nuestras consideraciones ordenanzas dadas específicamente para el Tucumán, como las de Abreu (1576) o las conocidas ordenanzas del oidor de la Audiencia de Charcas Francisco de Alfaro dictadas luego de su visita a la gobernación del Tucumán en $1612 .{ }^{9}$ Estos dos ordenamientos intentan regular las rela-

7 Por ejemplo, ley 15, título 14, libro V de 1596; ley 13, título 15, libro V y en especial ley 1 , título 1, libro VI de 1580 que transcribe textualmente la cláusula testamentaria de la reina Isabel la Católica.

8 Ley 12, título 1, libro VII de 1619; ley 11, título 10, libro V de 1530; ley 21, título 10 del libro VI de 1593.

9 Las primeras legalizaron el servicio personal sin distinción de sexo o edad, prohibieron la residencia de encomenderos o sus hijos en los pueblos de indios, el empleo de la fuerza de trabajo indígena en actividades de transporte, la saca de indios de los pueblos en fletes, etc. Las segundas, de Alfaro, suprimieron el servicio personal, establecieron la edad de tasa en 18 y 50 años y lo limitaron a los varones, prohibieron la figura del poblero o mayordomo de indios, etc. Sobre estas regulaciones y su efecto sobre la población indígena en esta localidad véase Piana, Josefina: Los indígenas de Córdoba... 
ciones interétnicas y se relacionan directamente con la justicia penal en cuanto definen nuevos delitos de la población hispánica en su trato para con el indígena.

El análisis que se presenta en esta oportunidad se realiza sobre la totalidad de los juicios penales interétnicos identificados en el Archivo Histórico de la Provincia de Córdoba ${ }^{10}$ desde la fundación de la ciudad (1573) y hasta el límite del siglo XVII. Se trata de más de treinta causas criminales en las que los miembros de la población indígena actúan como parte. Este número seguramente no se corresponde con las causas efectivamente substanciadas a lo largo de casi el siglo y medio que estudiamos, pues es previsible que un número indeterminable se haya perdido y otras menores se hayan substanciado de manera oral. Cabe destacar, además, que las causas por ebriedad que tienen una importante representatividad en este período, no se incluyen en este corpus en razón de que estos delitos se consideraron cometidos por el expendedor del vino; a los indios ebrios se los debía encarcelar hasta que recuperaran su sobriedad, pero legalmente no se les podía fijar costas por el encarcelamiento o para conseguir la libertad. ${ }^{11}$

El estudio de la acomodación de la práctica jurídica criminal interétnica no puede recurrir a las leyes citadas en alegatos y sentencias de los juicios pues éstos, con contadas excepciones, no citan normativa alguna. Pareciera que el delito penal hablara por sí mismo, expresara él solo la ilegalidad y por ello que no fuera necesario justificar su carácter de delito a partir del recurso a alguna ley previa. Los fallos, por su parte, tampoco se justifican y se introducen con la frase más o menos formularia "atento a los autos i meritos de este proçeso y la culpa que del resulta debo de condenar e condeno...." a la que le sigue directamente el castigo. Esta falta de fundamentación del texto de la sentencia fue común en la práctica castellana (no así la aragonesa). Es más, en 1768 Carlos III prohíbe que la sentencia se motive a fin de evitar posibles apelaciones. Sólo se encuentran dos excepciones a este enunciado general; la primera, en el año 1611, autoría del oidor de la Audiencia de Charcas Francisco de Alfaro, quien en su paso por Córdoba como visitador tuvo participación en dos causas incoadas a españoles por delitos contra indígenas. En una de ellas, contra el administrador de la encomienda del pueblo de La Escoba, Manuel Hernández, expresa de manera vaga y general que se lo condena por haber hecho tra-

10 En adelante, AHPC.

11 Borah Woodrow: "El estatuto jurídico de los indios en Nueva España", América Indígena, Vol. XLV, N.․ 2, México, 1985, pág. 270. 
bajar a los indios de más, "en contra de lo que disponen las ordenanzas". ${ }^{12}$ A fines del siglo se encuentra un único alegato basado en ley, autoría del protector de naturales quien, defendiendo a una india agredida por un negro, pide castigo "en cumplimiento de la ley diez y siete titulo octavo de la recopilaçion de indias". ${ }^{13}$

Por su parte, los protectores pueden alegar, sin citar, razones de derecho como atenuantes (que el indio estuvo dos meses en la cárcel y ello ya constituye una pena, que se ha de reputar el delito conforme la capacidad del sujeto, que se debe favorecer a los indios desvalidos, etc.). Esto es, edad, condición social, rusticidad, ignorancia y embriaguez constituyen los más importantes atenuantes que tienen en cuenta los defensores de naturales en sus alegatos, atenuantes que, debido a la falta de justificación de fallo, no podemos inferir hasta qué punto fueron tenidos en cuenta por el juez en el fallo.

\section{La divisoria étnica al interior del Derecho Penal}

\section{Jueces y defensores}

Según derecho, diferentes magistrados tenían competencia para actuar y proveer justicia en causas penales a indígenas (regidores, alcaldes de la santa hermandad, alcaldes ordinarios, tenientes de gobernador, gobernadores, etc.). Esto responde a una característica del sistema judicial indiano según la cual varios jueces y tribunales tenían la misma competencia y, según el principio de prevención, quien primero conocía de un caso, debía continuar la causa. En los asuntos que se iniciaban a instancia de parte, ésta era quien lo elegía. En córdoba se observa, sin embargo, que la jerarquía del acusado determinó la jerarquía del juez, sin que mediaran fueros especiales. Así, todas las instancias judiciales mencionadas actúan en la incriminación a indígenas, negros y mestizos por delitos penales, mientras que será exclusivamente el gobernador el que actúe contra los vecinos principales por agresiones a indígenas, a pesar de que era responsabilidad de los cabildos velar por el cumplimiento de las normas protectivas.

12 AHPC, Francisco de Alfaro contra Manuel Hernández por delitos cometidos contra los indios del pueblo La Escoba, Córdoba, 1611, escribanía 1, legajo 24, expediente 8, folios 184-194.

13 AHPC, El protector de naturales contra Nicolás, mulato, por haber maltratado a Micaela, india natural de la ciudad, Córdoba, 1695, escribanía 1, legajo 182, expediente 4, folio 57v-58r. 
Lo que interesa destacar aquí es que las justicias locales no actuaron en ningún caso inculpando a los vecinos principales por maltratos a indígenas, Es más, éstas no aceptaron, rechazaron y obstaculizaron posibles presentaciones o demandas realizadas por los indígenas en contra de los miembros de la elite local lo que se explica porque estos mismos jueces que aceptan o no una demanda son a la vez los representantes en el cabildo y los encomenderos de indios. Esta situación, en parte general para toda América, parece que fue especialmente eficaz en Córdoba del Tucumán pues por un lado, no se registra ningún caso en el que los indígenas denuncien a sus encomenderos. En segundo lugar, informaciones aisladas hablan de esta renuencia de los jueces locales a admitir reclamos indígenas contra españoles. Una causa civil expresa claramente esta situación cuando el protector que defiende a los indios ante la Audiencia expresa que "el dicho su encomendero como tiene rreferido se a servido dellos sin pagarles su trabaxo y aunque muchas vezes a ocurrido a la justiçia a pedir cumplimiento dellas no los an querido oyr por ser anssimismo ellos yntereçados como encomenderos de yndios y esta caussa no a podido alcansar justicia...". ${ }^{14}$

En tercer lugar, como hemos demostrado en otro trabajo, los indígenas advirtieron rápidamente esta situación y tomaron por estrategia para hacer escuchar sus reclamos aprovechar el paso del gobernador cerca de su pueblo de indios, y entonces presentar sus quejas ante esta autoridad, o recurrir directamente a la Audiencia de Charcas en búsqueda de justicia. ${ }^{15}$ El caso de los indios de Quilino ilustra respecto al primer caso, cuyo cacique presentó graves denuncias contra el poblero por maltratos, dexarretamientos, etc. al gobernador, aprovechando el paso de éste cerca de su pueblo de indios. ${ }^{16}$ No tenemos datos de causas criminales que hayan sido apeladas ante la Audiencia de Charcas, ni de presentaciones ante este máximo órgano judicial.

Las autoridades coloniales superiores denunciaron en sucesivos informes la opresión a la que estaban sometidos los indígenas de esta jurisdicción (y del Tucumán en general) y, específicamente en lo que respecta al funcionamiento de la justicia, en más de una oportunidad asumieron causas que no habían sido encausadas por los responsables locales. En el año

14 AHPC, Don Juan de Pacheco de Mendoza contra don Alonso de Leiva por los indios de Nondolma, Córdoba, 1636, escribanía 1, legajo 70, expediente 4, folio 14v-15r.

15 Bixio Beatriz y Constanza González Navarro: "Práctica de la justicia y resistencia indígena. Córdoba del Tucumán (siglos XVI y XVII)", en prensa.

16 AHPC, Gordillo, Alonso, por maltrato a los indios de Quilino, Córdoba, 1620, escribanía 1, legajo 50 , expediente 2 , folios 122-263. 
1592 el gobernador comienza una causa penal contra Juan de Burgos, vecino principal de la ciudad de Córdoba, pues un muchacho de su servicio se ahorcó en la despensa de su casa, lugar donde había sido encerrado por su encomendero por sospecha de robo. Entre los aspectos dignos de ser investigados según el gobernador, se hallaba el hecho de que no se hubiera realizado informe sobre este grave hecho. A poco de iniciadas las indagaciones, la situación se complica a partir del reconocimiento de que varios vecinos feudatarios tenían en sus casas instrumentos de castigo como cadenas, colleras, cornas, e incluso un cepo. Entre ellos, Alonso de la Cámara tenía en su casa nueve indios en prisiones a los que maltrataba y hacía trabajar en su beneficio. ${ }^{17}$ Todo esto, a pesar de ser contrario a la legislación, había sido tolerado por las justicias locales. ${ }^{18}$ En síntesis, si bien los jueces actuantes corresponden a los definidos por el derecho, la anomalía radica en su negativa a aceptar casos indígenas, en su inacción.

Una observación semejante podríamos hacer ya no en relación a los jueces sino a los defensores. En efecto, en la instancia de la defensa se siguieron también los pasos reglamentarios y los indígenas inculpados tuvieron, en todos los casos, el derecho a ser defendidos por un protector de naturales quien lleva adelante el juicio con verdadero compromiso hacia la causa indígena. Sin embargo, estos mismos defensores no aparecen en ningún caso inculpando a españoles sino que su acción se limita a la defensa de los indios cuando éstos son acusados por la justicia local, a pesar de que su función específica era velar por el cumplimiento de las disposiciones de amparo y defensa de los indígenas. ${ }^{19}$

\section{La enunciación de la culpa}

Que la justicia de la ciudad manifestó poco interés en la defensa del indígena se observa también en el hecho de que en ningún caso actuó de oficio en su favor. Una importante diferencia entre los juicios entablados a españoles y a indígenas radica en una variación en la "cabeza de proceso"

17 Este vecino actúa en 1616 como Protector de Naturales.

18 AHPC, Criminal contra Juan de Burgos por muerte dada a un indio, Córdoba, 1592-1594, escribanía 1, legajo 4, expediente 9, folios 138-198

19 Entendemos que esta situación ha confundido a algunos investigadores que aseguran que los Protectores de Naturales cumplieron sus funciones con responsabilidad y eficiencia (Véase Luque Colombres, Carlos: "Los protectores de naturales en Córdoba", Revista de la Junta Provincial de Historia de Córdoba, 15, Córdoba, 1993, págs. 91-111). 
que abre el juicio. En efecto, en las causas que el Estado entabla contra los nativos, la "cabeza” está compuesta por una narración del delito y una fórmula que explicita que se inicia un proceso criminal; mientras que en los juicios en los que se acusa a españoles por agresiones a indios o a indios por agresiones a indios, por el contrario, la "cabeza" incluye una narración y un pedido para que se admita la querella. Esta pequeña variante a nivel de proceso es de central importancia pues permite el establecimiento de dos grandes grupos de causas: 1. Causas penales o querellas promovidas por el Estado y 2. Causas penales o querellas promovidas por un particular (que deben ser admitidas por el Estado). En las primeras, el Estado acusa y él mismo se encarga de buscar las pruebas (o testimonios) de culpabilidad. En las segundas, los particulares que acusan deben demostrar tal culpabilidad y para ello presentan testigos ante el agente estatal. Lo interesante es que esta línea divisoria de causas es también una línea étnica: en todos los juicios consultados el Estado se erige en acusador, en enunciador de la denuncia cuando un natural ha agredido a personas o bienes españoles, y sólo en estos casos; esto es, la participación del Estado no depende de la naturaleza del delito sino de la filiación étnica del agredido, a pesar de que la legislación admitía ambas posibilidades como legales. El Estado delega esta responsabilidad a particulares, quienes presentan queja o querella y piden justicia, y les exige que demuestren la culpabilidad, cuando el agredido es un natural, sea que haya sido agredido por otro natural, un negro o mestizo, sea que lo haya sido por un español. Lo que el Estado defiende por sí es, entonces, a su grupo étnico de la acción de un solo grupo de sujetos peligrosos, los "otros". Encontramos que son los jueces quienes acusan, encarcelan y mandan recabar información en los casos de juicios a naturales que agreden cosas o personas españolas: "Diego Rodrigues de Ruescas alcalde de la Santa Hermandad en esta dicha ziudad dixo que andando corriendo la tierra .... tubo noticia que en el camino de Salsacate andaban unos yndios simarrones salteando y una noche.... y para castigo del conforme a su delito mando hazer y se hizo la ynformasion siguiente". ${ }^{20}$

Cuando el agresor es mestizo, negro u otro indio (nunca español, vecino principal) y el agredido indígena, es el indígena quien debe presentar queja ante la justicia: “... ante mi el dicho Diego Rodrigues alcalde de la Sancta Hermandad pareçio presente don Pedro yndio caçique del dicho pueblo (quezquezacat) y dixo que se quejava y quejo criminalmente de

20 AHPC, Proceso contra Cristóbal Agantalo, indio, Córdoba, 1600, escribanía 1, legajo 10, expediente 2 , folio $125 \mathrm{r}$. 
Sebastian de Raygada poblero del dicho pueblo de que el suso dicho abia muerto una yndia hija su legitima llamada Angelina la qual estaua enferma de sus berguenzas y que .... y me pidio le castigase y no lo firmo porque no supo firmar y firmelo yo porque no abia escribano ante quien pasase y ofreçio informaçion ...." ${ }^{21}$

De la misma manera, el indio Pascual, agredido por su ama quien lo ató a él y a su mujer y los "aporrio" con un palo, debe presentar querella criminal contra ella por intermedio de un protector de naturales, quien ruega al gobernador que admita la causa, a pesar de que el indio mostró ante la justicia sus espaldas, en las que se manifestaron las señales de los azotes. ${ }^{22}$ Don Alonso, cacique del pueblo de Anisacate, presenta querella civil y criminal contra Andrés, indio, por robo. Se presenta ante la justicia, hace la denuncia, entrega al indio para que sea apresado, y él mismo, el cacique, presenta sus testigos. ${ }^{23}$ De la misma manera, el protector de naturales querella criminalmente a Nicolás, mulato, por haber maltratado a una india, pide a la justicia que lo castigue y ofrece "informazion de lo nezessario". ${ }^{24}$

Hay tres juicios que podrían borrar esta divisoria. El primero trata del proceso contra Juan Barba, español, por amancebamiento con una india. No obstante, las alegaciones del acusado y el desarrollo de este corto juicio, revierten las acusaciones, hasta el punto que este acusado se convierte en acusador de indios que se le han huido, incluso acusador de la presunta india con la que estaba amancebado. De esta manera, el tratamiento discursivo de este texto lo acerca más a lo que conocemos como juicios a indios por delitos cometidos contra la población hispánica. No hay en él consideraciones que podrían indicar que se está defendiendo a la india y no a la moral de la sociedad española. ${ }^{25}$

Los otros dos juicios comenzados y asumidos por el Estado en la búsqueda de información sobre un delincuente no nativo han sido entablados por sujetos políticos exteriores a la ciudad de Córdoba y nos referimos a ello en el punto anterior. El primero, contra Juan de Burgos, lo promueve

21 AHPC, Proceso contra Sebastián de la Raygada, Córdoba, 1600, escribanía 1, legajo 10, expediente 5, folio $197 \mathrm{r}$.

22 AHPC, Proceso contra Pascual, indio, por maltratos, Córdoba, 1672, escribanía 1, legajo 137, expediente 8, folios 127-129 (cabe indicar que la causa está mal caratulada).

23 AHPC, Indio Alonso contra indio Andrés, por robo, Córdoba, 1642, escribanía 1, legajo 79, expediente 4, folios 109-113.

24 AHPC, El protector de naturales contra Nicolás por haber maltratado a Micaela, Córdoba, 1695, escribanía 1, legajo 182, expediente 4, 1695, folios 39-68.

25 AHPC, Proceso contra Juan Barba, verdugo, por amancebamiento con una india, Córdoba, 1628 , escribanía 1 , legajo 60 , expediente 12 , folios $152-154$ 
el gobernador Don Fernando de Zárate, y entre las averiguaciones intenta conocer no sólo el nivel de participación de Juan de Burgos en la muerte del muchacho indio, sino también por qué no se realizaron las averiguaciones correspondientes en el momento en que sucedió la muerte (“... si se hizo averiguacion dello e ynformacion por escrito e las demas diligencias..."), con lo que se demuestra que en este caso particular la justicia local de Córdoba no había actuado contra el español. ${ }^{26}$ El segundo juicio del Estado contra un español por maltrato a indios lo lleva adelante el oidor de la audiencia de Charcas, Francisco de Alfaro. ${ }^{27}$

\section{Los términos}

También en relación con los términos encontramos una situación semejante, esto es, cumplimiento sólo a nivel formal de las reglamentaciones vigentes sobre protección al indígena pero aprovechamiento de esta misma reglamentación para beneficiar al sector feudatario. El tiempo que un juez insume desde el primer conocimiento del delito hasta que da el caso por cerrado, esto es, hasta que el agente estatal llega a la "verdad", establece también una línea divisoria étnica. Los juicios a naturales son rápidos y suelen, en 15 días o menos, definir culpabilidades. A veces, en un solo día se buscan testigos e intérpretes, se toman juramentos, testificaciones y confesiones y, finalmente, se falla. La aceleración del proceso llega a extremos de no dar el tiempo necesario al protector de naturales para realizar la defensa, decisión que, a pesar de las amenazas de apelación por parte del protector, no es cambiada. Todo transcurre con fugacidad, con rapidez y, apoyados en la legislación de la época, que prescribía que las causas contra naturales fueran breves - con el objeto de no incomodarlos ${ }^{28}$ - se aprovechaba esta normativa para el castigo rápido. Así, por ejemplo, el primer juicio al indio Andrés por robo y agresiones a un español, se despacha en 14 días, al cabo de los cuales se dispone la amputación de su pie derecho. El segundo juicio, en 12 días, y el tercero, por haber huido de la iglesia en la que estaba recluido, en un solo día. En este día se lo juzga y se lo condena a muerte, a pesar de las quejas del protector de naturales porque se le ha dado una hora para

26 AHPC, Criminal contra Juan de Burgos ....

27 AHPC, Francisco de Alfaro contra Manuel Hernandez ....

28 Ley 10, título 10, libro $\mathrm{V}$ de 1514, 1530, 1551, 1618. Recopilación ..., Tomo II, páginas $158-159$ 
que busque testigos y pruebe la inocencia de su defendido. ${ }^{29}$ También en dos días se declara culpable al indio Cristóbal Agantalo, cuyo proceso se desarrolla entre el 24 y 26 de julio del año $1600 .{ }^{30}$ La causa más larga que conocemos duró 25 días y en ella se condena al indio Juan a 100 azotes "por las calles acostumbradas" por el robo de caballos. ${ }^{31}$

Por el contrario, las causas a españoles por agresiones a nativos suelen suspenderse por años, y sólo se retoman a solicitud de los nativos. Veamos un ejemplo: en el año 1613 se retoma, por pedido del cacique afectado, un juicio contra Cristóbal de Lomba, que había sido iniciado por el Licenciado Francisco de Alfaro el 6 de mayo de 1611. Los cargos contra este español son graves, considerados, incluso, desde el sistema de evaluación que establecía la normativa vigente. Cristóbal de Lomba entró dos veces al pueblo de indios de Chombihalón; tomó indios; los vendió; los llevó atados y en colleras al valle de Catamarca, muriendo en el viaje de sed dos muchachos; azotó "con mucha crueldad" al cacique; robó a los indios objetos y ganado, etc. A pesar de que la justicia de La Rioja liberó un número importante de indígenas y los dejó volver a su natural para que sirvan a su encomendero, Cristóbal de Lomba no fue, en aquella oportunidad, castigado. El juicio se reinicia el 17 de octubre de 1613 por pedido del cacique agredido, y el 25 de septiembre de 1614 la justicia ordena prender al delincuente y traerlo preso a la ciudad. Desconocemos el desarrollo posterior de esta causa porque el juicio está inconcluso. ${ }^{32}$ De la misma manera, el juicio contra Juana de Pedernera por maltratos fue suspendido porque el juez debió ausentarse de la ciudad. Desconocemos si posteriormente éste continuó. ${ }^{33}$

\section{La extensión del daño: el daño social y el daño individual}

Hemos indicado que cuando se agreden cosas o bienes españoles, y cuando el agresor es un nativo, es el Estado el que asume la función de acusar. En tanto se ha dañado a la sociedad entera — no sólo a un particularel Estado, al recibir la noticia de un presunto delito, cuya fuente se explici-

29 AHPC, Criminal contra Andrés indio por robo, Córdoba, 1592-1598, escribanía 1, legajo 6, expediente 3, folios 173-217.

30 AHPC, Proceso contra Cristóbal Agantalo...

31 AHPC, Proceso contra Juan, indio, por robo de caballos, Córdoba, 1619, escribanía 1, legajo 48, expediente 9 , folios 148-160.

32 AHPC, García, cacique del pueblo de Ambihalon, contra Cristóbal de Lomba, por maltratos, Córdoba, 1615, escribanía 1, legajo 34, expediente 8, folios 237-248.

33 AHPC, Proceso contra Pascual, indio .... 
ta o no en la cabeza del proceso ("a mi noticia ha venido"), comienza el procedimiento de averiguación de la verdad. Es así que los juicios penales a naturales se inician con un pedido de información por parte del juez actuante sobre la conducta de un particular, el sospechoso.

Que el delito es un daño a la sociedad colonial y no tanto a un particular damnificado, queda claramente expresado en una causa en la que se acusa a un mulato de haber maltratado cruelmente a una india que había sido enviada a la noche por su ama a la pulpería, con la que "pretendio tener exzesso". En el juicio se expresa claramente que el negro debe ser castigado "para su escarmiento y que a otros les sirva de ejemplo porque de otra manera no habra vecino desta ciudad que se atreva a despachar su jente de serviçio a lo que se les puede ofrezer en grave perjuicio de la causa publica..." ${ }^{34}$ Esto es, la oración causal expresa claramente que no interesa la agredida, la india, sino el hecho de que, en caso de que estos hechos se generalicen, los españoles no podrán despachar su gente de servicio y así satisfacer sus necesidades. El castigo tiende así a anular un peligro virtual para la población de origen europeo.

Esta idea de que el delincuente agrede a todo el cuerpo social la encontramos explicitada en las causas a miembros de la población nativa. Sin embargo, en ninguna oportunidad se explicita en las causas a españoles por delitos penales contra indígenas. Desde el momento en que la averiguación de la verdad y el castigo del delincuente es un proceso que se encuentra en manos de agentes reales, es una responsabilidad que toma el Estado para sí, pues se trata también de un atentado a la soberanía real. Toda subversión del orden estatuido se considera un delito y, básicamente, como un delito contra la sociedad; las consecuencias negativas que este delito pueden implicar para el sujeto nativo particular no parecen ser de importancia. En el caso de los juicios entablados a españoles, debido a que éstos deben ser admitidos por el juez, en la cabeza del proceso no se hace referencia alguna al daño social, y simplemente el representante del nativo agredido pide castigo, por lo que entiende es un daño a una persona individual.

\section{La función de la acción judicial}

Las funciones del actuar de la justicia se dividen, coherentemente, en la línea que separa étnicamente al delincuente. Cuando los miembros de la

34 AHPC, El protector de naturales contra Nicolás .... folio 39v. 
población nativa delinquen, su proceso y penalización se entienden como un acto de castigo y ejemplificación para el resto de los naturales. Así, en las "cabeza de proceso" de los juicios criminales se especifica que la razón de la justicia es el ejemplo, impedir que otros naturales cometan delitos: "... de donde a resultado los daños referido y para que no suceda otros mayores azia e ize cabeça de proceso contra el dicho Andres al qual su majestad el dicho alcalde le tiene preso para que a el sea castigado conforme a la gravedad de sus delitos e para que a los demas naturales aya exemplo ..." ${ }^{35}$. En otro juicio se especifica:"... para que le sea escarmiento y castigo y a otros ejemplo dando satisfacion a la vendieta publica para que con eso les sirva de freno y miedo a los malhechores...."36

También en los fallos se insiste en el carácter ejemplificador de la pena: “... le sea quitado el cabello y luego ahorcada del pescueso hasta que naturalmente muera con una soga para que en ella sea castigo y en otras exemplo ...". ${ }^{37}$ Este carácter ejemplificador de la pena explica la espectacularidad que rodea al castigo: es necesario que todos los nativos sean partícipes del castigo, que se atemoricen y así desistan del deseo al daño. Forman parte del suplicio (muerte, amputación o azotes) el pregonero "que manifieste sus delitos" por toda la ciudad y la visibilidad que se le exige a la pena, la que se lleva a cabo en la plaza pública. Esto es, el ejemplo cumple con su función, es posible, sólo en tanto el castigo sea espectacular y visible: “... sea sacado en una vestia con una soga al pescueso y atadas las manos y con boz de pregonero que manifieste su delito sea llevado por las calles y plaza acostumbrada hasta el rollo desta ciudad y alli sea ahorcado hasta que muera naturalmente y ninguna persona sea osado de le quitar del dicho rollo sin licencia ni mandado mio so pena de muerte natural ..." 38

Es interesante destacar que en los juicios a españoles originados en delitos contra indígenas no se menciona la ejemplaridad, y por ello el castigo tampoco es espectacular. Ni siquiera el que lleva adelante Alfaro, oidor de la Audiencia de Charcas, contra un poblero. En este caso el actuar de la justicia no tiene carácter ejemplificador sino reparador: se busca enmendar el daño ocasionado por el poblero y, por ello, la finalidad es el pago a los nativos de lo que se les ha obligado a trabajar de más. Se busca "satisfazer

35 AHPC, Criminal contra Andrés ...., folio 173r.

36 AHPC, El protector de naturales contra Nicolás...., folio 47v.

37 AHPC, Criminal contra María, india, por haber echado solimán en la tinaja de su ama, Córdoba, 1619, escribanía 1, legajo 48, expediente 8, folio 143r y v.

38 AHPC, Criminal contra Andrés...., folio 202v. 
a los indios del pueblo Descoba”. Se lo condena a cuatro años de destierro, a pagar 30 pesos para gastos de visita y 100 pesos para los indios del pueblo de La Escoba. ${ }^{39}$

\section{Lo reprimible: El sistema de transgresión}

En tanto mediante el derecho penal se reprime lo que damnifica a la sociedad, lo que constituye un daño social, una perturbación para el conjunto de la sociedad, el sistema de penalizaciones nos ubica en los criterios que esa sociedad ha manejado respecto de lo que merece ser resguardado y lo que no. El delincuente es un enemigo social, un enemigo interno. ¿Qué se penaliza en relación con los nativos? ¿Qué mal se pretende reparar o impedir contra el cuerpo social?. Acordamos con Michel Foucault en que los delitos y las penalizaciones son relativas y dependen de las necesidades de las sociedades. ${ }^{40}$ Es por esto que nos preguntamos: ¿a qué le teme la sociedad colonial cordobesa? ¿Cuáles son las conductas de los nativos consideradas "peligrosas"? ¿Cuál es el grado de peligrosidad, medido por la severidad del castigo que se inflige? ¿Qué necesidades viene a cubrir el castigo?.

En principio, en los juicios que se han conservado en el AHPC predominan las causas por vagancia y robo. Estas transgresiones afectan directamente a las cosas, a la propiedad de los españoles, afectan a sus objetos y a la capacidad de producción de sus tierras, en tanto el indio suelto, libre, no trabaja: “... es ladron y huidor y çimarron y a muchos dias que anda huido y no sirve al dicho Francisco Mexias su amo ...". ${ }^{41}$ Por otra parte, estos juicios a indios cimarrones, que robaban ganado de los campos, eran duramente reprimidos, especialmente en los primeros decenios posteriores a la conquista, pues el ganado europeo constituía un bien preciado, caro y escaso, y los mayores obstáculos para su reproducción provenían de las andanzas de los indígenas que lo robaban y consumían subrepticiamente. ${ }^{42}$ Es por

39 AHPC, Francisco de Alfaro contra Manuel Hernández.... folio 191r.

40 "Cada sociedad deberá modular, según sus propias necesidades, la escala de penas ... el castigo no se deriva de la falta en sí misma, sino del perjuicio causado a la sociedad o del daño que le inflige .... En consecuencia, no hay un modelo universal de la penalidad, sino una relatividad esencial de las penas". Foucault, Michel: La vida de los hombres infames, Ediciones La Piqueta, Madrid, 1993, pág.54.

41 AHPC, Proceso contra Cristóbal Agantalo...., folio 126r.

42 Assadourian: El sistema de la economía colonial...., pág. 31. 
ello que estos delitos son calificados como "graves y atroces" en la documentación, calificación que se compadece con la magnitud de los castigos que merecen (entre 50 y 100 azotes en la plaza pública y corte del cabello), penalizaciones corporales e infamantes, espectaculares y visibles que inscriben en el cuerpo de la víctima su delito, la humillan. Con el corte del cabello — "trasquilar" - se busca estigmatizar a la víctima, la que junto a su cabello pierde su valor social y el respeto del endogrupo, de acuerdo con las normas nativas.

Hay otra razón, quizá la más fuerte, para reprimir todo intento, por débil que sea, de oposición al sistema colonial. En un núcleo poblacional relativamente reducido y alejado de otros centros, rodeado por población hostil, era prioritario controlar la vida y la conducta de cada uno de los actores que constituyeran virtuales enemigos. Este hecho explica la existencia de una justicia que se impone con mayor severidad a la vagancia, de una justicia intolerante contra el indio "suelto", "cimarrón", que no obedece la normativa impuesta por el sistema colonial.

Las agresiones contra sujetos también son atravesadas por esta línea étnica en la que la pena más grave se aplica a las agresiones físicas o de palabra de un indígena a un miembro perteneciente a la población española. No hemos encontrado, en este tipo documental, casos de nativos que directamente maten a españoles, ${ }^{43}$ sólo pedradas, persecución o presunto intento de envenenamiento a españoles son delitos suficientes para provocar la pena de muerte del delincuente cuando éste es nativo. Estas agresiones son las más reprimidas, las más graves, las más controladas. La pena de muerte es en este caso la primera solución, aunque puede ser apelada, y en algunos casos cambiada, especialmente cuando la apelación viene avalada por fianza y/o pedido de un religioso. ${ }^{44}$ Los castigos corporales buscan el dolor físico, y en el caso de la amputación de un miembro, se busca también la "marca" del delincuente pues se graban en su cuerpo las huellas del poder. ${ }^{45}$ Se le inscribe en el cuerpo un atributo profundamente desacredita-

43 En otros tipos documentales pueden reconocerse algunos ejemplos: la muerte de Blas de Rosales y de su yerno, Diego de Cáceres por parte de los nativos de Ongamira (AHPC, Investigación por muerte de Blas de Rosales, Córdoba, 1573, escribanía 1, legajo 1, expediente 1) o la muerte de Diego de Funes y su cuñado, Gaspar González Jaimes, por los indios de su encomienda (Archivo Municipal de la ciudad de Córdoba, acta capitular de la ciudad de Córdoba del 11 de agosto de 1596).

44 AHPC, Criminal contra María, india, por echar.....

45 Borah: "El estatuto jurídico ..." encuentra que en Nueva España no se ha recurrido a la pena de la amputación, situación que hallamos documentada en Córdoba, en las primeras décadas de asentamiento europeo, en dos oportunidades y en ambas tenemos noticias ciertas de que ésta se consumó 
dor que lo acompañará a lo largo de su vida; que actualizará su pasado delictivo ante sí mismo y ante los demás permanentemente. Se trata de un estigma. ${ }^{46}$ Tan pública es esta marca, tan esencial al sujeto peligroso, que pasa a formar parte de su identidad personal. En el caso del tercer juicio al indio Andrés, ya mencionado, se observa que una vez producida la amputación, el indio pasa a ser denominado "indio Andrés cortado un pie" o "Andrés desxarretado". Llama la atención que los largos escritos del escribano de esta causa no economicen formas para la mención del indio, y repitan en un mismo folio esta nominación perifrástica una y otra vez. El estigma se ha incorporado a la identidad del indio, a su nombre propio. ${ }^{47}$

Estos delitos, jerárquicamente más peligrosos para la sociedad de origen español se corresponden también con castigos más graves pero apelan a las mismas estrategias: humillación social, dolor corporal hasta la eliminación del sujeto y estigma. Es posible, incluso, que estos tres castigos se conjuguen en una misma persona y en un mismo tiempo. Así, en el primer fallo a la india María por presunto envenenamiento se la condena a 100 azotes en las calles públicas, la quita del cabello al pie de una horca "de tres palos" y finalmente, a que sea "ahorcada del pescueso". ${ }^{48} \mathrm{Al}$ indio Cristóbal Angatalo se lo condena a cien azotes, corte del cabello y "ansi mesmo le sea cortado el pie derecho por el empeyne del y con esto sea entregado a su amo". Sólo conocemos un caso en el que el proceso culmina con la aniquilación efectiva del delincuente y, en este caso, la magnitud del castigo buscó también espectacularidad, visibilidad; se condena al indio “... a que de la carsel y prision en que esta sea sacado con una soga al pescuesso y atadas las manos y asi sea llevado por las calles acostumbradas con boz de pregonero que manifieste sus delitos y con esto sea llevado al rollo desta çiudad y alli sea colgado por el pescuesso hasta que muera naturalmente" ${ }_{49}$

Un castigo igualmente doloroso, y según parece ubicado en un nivel inmediatamente inferior al de la pena de la muerte, lo constituye el exilio, la marginación social del acusado. Si el indio es de la ciudad, se lo castiga

46 Goffman, Irving: Estigma, Madrid, 1987.

47 AHPC, Criminal contra Andrés...

48 Este fallo fue apelado por el protector de naturales pero le fue denegada la apelación. Interviene entonces la iglesia dando el dinero necesario para que se consume y amenazando al juez “... y de lo contrario protesto de dar quenta dello a la Real Audiencia de la Plata". Frente a esta situación, el juez cambia el fallo por el destierro de la india por cuatro años. AHPC, Criminal contra María, india, por echar...

49 AHPC, Criminal contra Andrés..., folio 216v 
a no acercarse a ella, si forma parte de un pueblo de indios, se lo castiga a no entrar a él.

El sujeto peligroso por excelencia es, entonces, el que agrede a personas españolas. Que los atentados a las personas españolas (así sean de palabra) son delitos más graves que los robos queda también demostrado en el hecho de que las acusaciones de los primeros se textualizan con profusos subjetivemas negativos, ausentes en los segundos.

Hay otro conjunto de delitos que no se inscribe en el sistema "oficial" de la transgresión, que no se castiga directamente pero sí se alega como refuerzo a las argumentaciones: son delitos que surgen en el entorno de otros. Así, por ejemplo, en el juicio que entabla Juan Céliz de Quiroga, en nombre de la india Antonia de su propiedad, contra el indio Cristóbal, el delito fundamental que se le imputa es haberle hecho malos tratos, cuyas heridas son "manifiestas en la cara y cuerpo de dicha yndia para cada y cuando se quisiere ber". Sin embargo, a lo largo de sus acusaciones surgen otros cargos, que refuerzan este primero, y que en la textualización se van priorizando, de manera que al cabo de la acusación de este encomendero parece que los delitos graves son más bien otros: el hecho de que el indio Cristóbal haya estado amancebado con la india a lo largo de tres años ("por estar con ella mal amistado abra tres años con color de que era su mujer"; "aver estado tres años en ofensa de Dios con capa de su mujer como lo confiesa en su declaracion dicho yndio"); el hecho de que el indio Cristóbal era casado en Santiago del Estero y no llevara "vida maridable", lo cual escandaliza a la sociedad y ofende a Dios. En realidad, la justicia defiende tanto los bienes como la moral cristiana de la sociedad, y continuamente encontramos que estas razones aparecen integradas. Pero para Juan Céliz de Quiroga el indio Cristóbal merece ejemplar castigo porque, por sobre todas las cosas " el mayor delito fue el dentrar a mi casa saltando las paredes como tiene confesado dispuesto por esa causa a padeser mi presuncion y en rason por ser onbre prinsipal y tener donsellas y sobrinas en ella". Esto es, el mayor delito, una vez más, fue el de poner en peligro la integridad de personas españolas. Llevar el cabello atado, calzar espuelas muy grandes, lazos en las ancas, correr por las calles públicas o ir al río "a inquietar las indias negras y mulatas" constituyen otros tantos delitos que hacen peligrosa la conducta del nativo — que habían sido publicados en un bandoy que se alegan como refuerzo.

Si el agresor es un español que ha producido la muerte o graves maltratos a nativos, la pena es más benévola y se paga, como hemos indicado, 
con el exilio o con multa. Diferencias en la severidad de la justicia según la jerarquía social del agredido y del agresor. Se trata de una justicia que actúa según principios que emergen de los parámetros valorativos de la sociedad colonial en la que se aplica: distintos sistemas de transgresión, distintas conductas peligrosas, distintas tácticas punitivas según sea la filiación étnica del transgresor. Esta división fue absolutamente legal pues ya desde las Partidas se establecía que a los hidalgos no les correspondían penas humillantes. Sin embargo, como hemos intentado demostrar, en Córdoba del Tucumán esta legalidad no actúa sino como marco para la ilegalidad.

Desde la fundación de la ciudad y a lo largo de todo el siglo XVII este conjunto de conductas definidas como "peligrosas" no varía. No se observan redefiniciones del sujeto "temible", no surgen nuevas transgresiones que puedan constatarse con el corpus que ha llegado hasta nosotros. ${ }^{50}$

La ley penal no busca corregir al sujeto, es así que la cárcel, la prisión, no constituye en ningún momento un castigo o un lugar de asilo del sujeto peligroso. La cárcel está para "guardar" al sujeto hasta que se demuestre su culpabilidad o inocencia, luego de lo cual viene la pena. Así, la pena no puede ser la prisión, porque no se busca la corrección del sujeto. En este siglo las medidas contra indios cimarrones no buscan el disciplinamiento o la disponibilidad de la fuerza de trabajo. Parece que la hipótesis más convincente es la del temor.

\section{La política de la justicia}

Hasta aquí hemos demostrado que en la localidad de Córdoba del Tucumán la justicia criminal actuó respetando la normativa en cuanto a jueces, defensores, acusadores, penas, mitigadores, etc. Esto es, se siguieron las disposiciones legales tanto en el procedimiento como en las penas. Cuando actuó, la justicia lo hizo de derecho y se observa el cumplimiento de la norma pues la pena en todos los casos es legal. De la misma manera, el conjunto de disposiciones a aplicar no parece haber sido amplio o heterogéneo. Por el contrario, transgresiones y penas a los indígenas constituyen un sistema muy cerrado: al intento de homicidio con agravantes (reincidencia o traición), le corresponde la pena capital (horca); al hurto

50 A fines de siglo se asiste a un nuevo peligro, que será juzgado y penalizado con rigor: el nativo o mestizo con atributos españoles, es decir, que se viste como español, que esconde su condición y aparenta ser descendiente de españoles. En el corpus no se incluyen juicios que penen este delito. 
(abigeato) o huida de la encomienda le corresponden penas corporales y penas infamantes (azotes, corte del cabello); la reincidencia en estos delitos aumenta la pena corporal: corte del pie.

No se observan regionalismos o particularismos en cuanto a la resolución de problemas interétnicos por la vía judicial, ni variaciones en cuanto a las atribuciones de los funcionarios. Tampoco hemos podido definir casos en los que se alegue o se funde un derecho en el recurso a la costumbre, la normativa indígena o la opinión de juristas, situación común en los juicios interétnicos civiles, en especial, aquellos en los que españoles e indígenas litigan por tierras.

En relación con las apelaciones es interesante reconocer que, hasta donde hablan los juicios estudiados, no ha habido causas en las que se apele a la Real Audiencia, a pesar de que sus atribuciones principales eran las de justicia, atendiendo en grado de apelación en pleitos civiles y criminales. La audiencia de Charcas, que con tanto celo intentó prevenir los abusos de jueces inferiores, no parece que tuvo mayor injerencia en la justicia penal en Córdoba, con excepción de los juicios llevados a cabo por el oidor Alfaro en el año 1611.

Sin embargo, surge, por un lado, la indicación de que, por un lado, las justicias locales no admitieron las presentaciones indígenas en ningún caso; por otro, las penas impuestas son siempre las mayores previstas por la legislación. En tercer lugar, no se observa que se aleguen o consideren disposiciones claramente protectivas, así como no se cumplieron aquellas que establecían que se debían castigar con mayor rigor los delitos en que las víctimas son indios respecto de los cometidos contra españoles. En las causas analizadas destacan las continuas referencias a innumerables situaciones de castigo a los indígenas que no desembocaron en la justicia, esto es, que corrieron por vías extrajudiciales. Por indicaciones incluidas en los mismos juicios analizados y en otras fuentes de la época, se infiere que el castigo, el control, la represión y la prevención del delito encontró otros caminos, más rápidos, y quizá eficaces, de modo que la justicia fue sólo una de tantas opciones. En realidad, toda la sociedad colonial queda involucrada en este ejercicio del castigo. En el interior del endogrupo nativo la represión no se encuentra nunca en la cabezas políticas, en los caciques, sino en una instancia intermedia, el yanacona, verdadero articulador de las sociedades, quien se aseguraba de esta manera la sumisión y el trabajo de los nativos, especialmente en el interior de la encomienda, espacio en el que desarrollaron su labor, organizando el trabajo de los indígenas y garan- 
tizando la productividad. Así, unos indios que han huido del servicio de su encomendero confiesan que "... se huyeron de myedo de los açotes que les daba un anacona llamado don Pedro, del servicio de Juan de Aguilar poblero y anacona .... que los açotaba para que trabajen en la açequia..." ${ }_{51}$

Este mismo poder ilegal, represivo, es ejercitado por otro sujeto actuante en el interior del sistema de la encomienda, el mayordomo o poblero $^{52} \mathrm{y}$ a pesar de que desde el año 1611 (Ordenanzas de Alfaro) estaba prohibido que residieran en el mismo pueblo de los indios, los pobleros recibieron permisos especiales por lo que esta figura se continúa, sin atenuar su crueldad. La arbitrariedad de estos administradores fue claramente descrita por el oidor Alfaro, quien en carta al rey expresó que "es la mas mala gente que el mundo tiene". ${ }^{33}$ Especialmente elocuente, por su crueldad y arbitrariedad, es el juicio al administrador de la encomienda de Quilino, Alonso Gordillo, acusado por los indios por practicar justicia privada, desxarretar, azotar, trasquilar a los indios, prohibir los casamientos, etc. ${ }^{54}$

En el entorno de la familia española, tanto el amo como la ama y sus hijas son otros tantos ejercitadores de la fuerza del poder cuyos objetivos son difíciles de dilucidar, todo lo cual consta también en los documentos como dato secundario, no punible, como un mitigante que se intenta alegar para justificar la acción delictiva del nativo, pero que la justicia no cree necesario investigar y que tampoco tiene en cuenta en el momento de inculpar. Las autoridades políticas y judiciales de la ciudad toleraban también que en las casas de algunos particulares, vecinos principales, existieran instrumentos de castigo y tortura, a pesar de que ello estaba expresamente prohibido por la legislación.

A partir de estas primeras localidades de relación interétnica, la represión y el castigo actúan en la vida cotidiana de la población nativa, buscando su aprovechamiento, su sumisión, o simplemente, buscando presentarse como "autoridad", en el proceso de consolidación del poder real en estas latitudes. Esta parece haber sido la estrategia colonial más eficaz en esta gobernación durante el siglo XVII, mucho más que la judicial, empleada

51 AHPC, Criminal contra Juan de Burgos ....., folio 146v.

52 Sus funciones fueron reglamentadas por las Ordenanzas de Abreu (1576), quien intentó limitar su poder y autoridad, aunque en la práctica sus medidas no fueron eficientes. Esta figura, por lo general, coincidió con la del administrador de la encomienda, aunque en otras regiones del Tucumán estas funciones podían estar a cargo de personas diferentes.

53 Larraouy, Antonio: Documentos del archivo de indias para la historia del Tucumán, Buenos Aires, 1923, pág. 34. Sobre este mismo tema véase también Mayo, Carlos: "Los pobleros del Tucumán colonial", Revista del Historia de América, 85, México, 1978, págs. 27-57.

54 AHPC, Gordillo, Alonso, proceso por maltrato.... 
básicamente, como hemos indicado, para el caso de los indios cimarrones. A juzgar por el número de causas conservadas, y aun asumiendo que muchas de ellas se han perdido, parece que el recurso a la justicia escrita no constituyó ni para los indígenas ni para la población española una estrategia importante, sea para defender los propios derechos, sea para conservar o establecer cierto orden social, sea como estrategia de control social, u otros. La acción de la justicia se extiende a indios cimarrones y a averiguaciones de crímenes de indios que aparecen muertos en caminos, ríos o haciendas, o cuando el delito es tan atroz que hay que asegurar la eliminación del delincuente, de manera visible y ejemplificadora. Delitos de otro orden se solucionaban, todo parece indicar, en el ámbito exterior a la justicia oficial.

La línea divisoria étnica separa los jueces actuantes, el compromiso del Estado local, los tiempos que insume la investigación de la verdad, la extensión del daño (social/individual), el sistema de la transgresión, así como la naturaleza de la pena. Así como el juez es autoridad política a la vez que militar y judicial (capitán general, gobernador y justicia mayor es el título con el que se presentan los jueces; o capitán general y justicia mayor), la frontera entre la justicia y la política es también indefinida. La justicia de carácter estamental es un instrumento de la política colonial.

En síntesis, tomando las causas de manera descontextualizada de otros hechos de naturaleza histórica, todo confluye a la consideración de que la ley penal interétnica se respetó cuidadosamente en esta ciudad pues jueces, defensores, términos, delitos y castigos responden a derecho. No obstante, no fue por su acción sino por su inacción que se actuó contra derecho. Los datos acercados, unidos al hecho de que las sumarias averiguaciones por muerte de indios no se resuelven en ningún caso, ni la justicia manifiesta interés en resolverlas, parecen indicar que la justicia de la ciudad actuó como un cordón defensivo de los vecinos principales de origen español ${ }^{55} \mathrm{y}$ en este sentido tuvo un efecto determinante sobre la estructura social y económica colonial pues estas políticas judiciales fueron en buena medida las responsables de la consolidación del régimen colonial en esta localidad en tanto aseguraron - mediante su inacción - la formación de los primeros capitales que harán de Córdoba en la segunda mitad del siglo XVII una de las ciudades más importantes de la gobernación.

55 En el Tucumán, así como en el Río de la Plata, la solidaridad del grupo encomendero sólo se mantuvo frente a los del afuera y ello no significó que no hubiera profundos conflictos al interior de la elite. Ver García Belsunce, César: "La sociedad hispano criolla", Nueva Historia de la Nación Argentina, Academia Nacional de Historia, Buenos Aires, 1999, II, págs. 149-181. 